\title{
Cost-Effectiveness of Infliximab for the Treatment of Acute Exacerbations of Ulcerative Colitis in the Netherlands
}

Mohammad A. Chaudhary • Tao Fan

To view enhanced content go to www.biologicstherapy-open.com Received: October 3, 2012 / Published online: December 21, 2012

(C) The Author(s) 2012. This article is published with open access at Springerlink.com

\section{ABSTRACT}

Introduction: Infliximab is registered for the treatment of moderate-to-severe active ulcerative colitis (UC) adult patients who have had an inadequate response, or are intolerant, or have medical contraindications to therapy including corticosteroids and 5-aminosalicylates or thiopurines (6-mercaptopurine [6-MP] or azathioprine $[\mathrm{AZA}])$. The authors estimate the costs and effects and evaluate the costeffectiveness of infliximab at the licensed dose of $5 \mathrm{mg} / \mathrm{kg}$ versus cyclosporine or surgery for the treatment of adult Dutch patients hospitalized

M. A. Chaudhary $(\bowtie)$

Health Economic Statistics, Merck Research Labs, Mail Stop: UG-1C60, 351 N. Sumneytown Pike,

North Wales, PA 19454-2505, USA

e-mail: mohammad_chaudhary@merck.com

T. Fan

Merck \& Co., Inc., 1 Merck Drive,

Whitehouse Station, NJ, USA

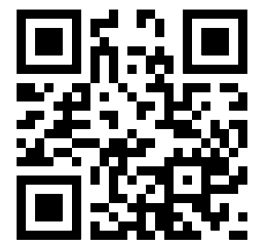

Enhanced content for this article is

available on the journal web site:

www.biologicstherapy-open.com with acute exacerbations of UC, refractory to intravenous steroids.

Method: An existing decision analytical model was updated to simulate disease progression of hospitalized UC patients in the Netherlands, refractory to intravenous corticosteroids, and to estimate the costs and benefits associated with infliximab compared to cyclosporine and surgery over a 1-year time horizon. Colectomy rates were derived from infliximab and cyclosporine randomized trials and synthesized using multiple treatment comparison methods. The utility estimates associated with health states of ulcerative colitis patients were obtained from the literature. Resource use and drug use frequencies as well as unit costs were obtained from Dutch sources. The primary effectiveness measure used in the analysis was quality-adjusted life years (QALYs).

Results: For a typical UC patient with body weight of $70 \mathrm{~kg}$, the costs of treatment with infliximab, cyclosporine, and surgery over a 1 -year treatment period were $€ 17,062, € 14,784$, $€ 13,979$, respectively. The associated numbers of QALYs were $0.80,0.70$, and 0.58 for infliximab, cyclosporine, and surgery respectively. The incremental cost-effectiveness ratio for infliximab 
was $€ 24,277$ per QALY gained compared to cyclosporine, and $€ 14,639$ per QALY gained compared to surgery.

Conclusions: Infliximab induction regimen appears to be a cost-effective treatment option in comparison to cyclosporine and surgery for hospitalized patients with acute exacerbations of UC, refractory to intravenous corticosteroids in the Netherlands.

Keywords: Colectomy; Cost-effectiveness; Cyclosporine; Gastroenterology; Infliximab; The Netherlands; Ulcerative colitis

\section{INTRODUCTION}

Ulcerative colitis (UC) is characterized by chronic inflammation of the mucosa of the colon. The symptoms of UC vary according to the extent and severity of the inflammation. Symptoms include bloody diarrhea, abdominal pain, anemia, fatigue, weight loss, rectal bleeding, and loss of appetite. A Dutch study demonstrated that UC influences daily functioning, predominantly when patients have a high disease activity [1]. Especially, loss of energy as a consequence of an active disease is an important limitation in daily activity for UC patients. Patients with UC experience lower quality of life because of loss of energy, negative self-image, social fear, dealing with a chronic disease, and lack of information provided by health care staff $[2,3]$. Quality of life for UC patients is affected by both the symptoms associated with disease and by treatments and related adverse effects [4].

According to the Dutch Health Care Insurance Board, it is estimated that the incidence of UC is approximately 10-12 per 100,000 per year with a reported prevalence of 70-150 per 100,000 [5]. Based on these prevalence figures, there are between 17,000 and 35,000 people in the Netherlands with UC.

Cost of illness of inflammatory bowel disease (IBD) in the Netherlands in 2005 was $€ 118.6$ million; $0.2 \%$ of the Dutch healthcare budget. Most costs were incurred by the people aged $25-44$ years and $70 \%$ of all costs of illness were spent on hospital care and specialists [6]. According to Odes et al. [7] the mean annual total expenditure on health care was $€ 1,524$ per patient year for UC in Europe and Israel. Furthermore, among Dutch patients with IBD, labor force participation was $6.5 \%$ lower and chronic work disability $17.1 \%$ higher than the age and gender matched general population [8].

Infliximab is an inhibitor of tumor necrosis factor- $\alpha$ (TNF- $\alpha$ ), a cytokine that plays an important role in the pathogenesis of UC [9]. Infliximab is registered for treatment of moderately-to-severely active UC in adult patients who have had an inadequate response to conventional therapy including corticosteroids and 5-aminosalicylates or 6-mercaptopurine (6-MP) or azathioprine (AZA), or who are intolerant to, or have medical contraindications for such therapies in randomized controlled trials, Active Ulcerative Colitis Trials 1 and 2 (ACT 1 and ACT 2) [10]. Infliximab has also been used to avoid surgery in patients with acute exacerbations of UC $[11,12]$.

Infliximab induction regimen was shown to be a cost-effective treatment option compared to surgery for UC patients hospitalized with an acute exacerbation in the UK [13]. Scheduled maintenance treatment with infliximab has been shown to be cost-effective in moderateto-severe UC patients [14].

The objective of this study is to estimate the costs and effects and evaluate the costeffectiveness of infliximab at the licensed dose of $5 \mathrm{mg} / \mathrm{kg}$ versus cyclosporine or surgery for the treatment of adult Dutch patients 
hospitalized with acute exacerbations of UC, refractory to intravenous (IV) steroids.

\section{METHODS}

\section{Model Overview}

A decision analytic model, developed earlier [13], was used to simulate the progression of a hypothetical cohort of Dutch patients hospitalized with an exacerbation of UC and treated with cyclosporine or surgery and to track the associated costs and outcomes. The model was updated and adapted to conform to the treatment practice in the Netherlands $[2,15,16]$. The base case time horizon of 1 year was used based on the observation periods of available published evidence [10, 11, 17] and was varied up to 10 years in the sensitivity analysis. Because of different characterization of treatment outcomes (see Fig. 1) the base case period was divided into two treatment cycles (0-3 and 4-12 months) and a decision tree structure was considered more appropriate than a Markov modeling framework.

The initial model cohort consisted of severely active UC Dutch adult patients with an average weight of $70 \mathrm{~kg}$ hospitalized with acute exacerbation of the disease and not responding to $72 \mathrm{~h}$ of IV steroid therapy. These patients received one of the three treatments: infliximab, cyclosporine, or surgical intervention. The treatment options and the treatment pathways are shown in Fig. 1. The goal of medical treatments was to avoid colectomy and induce remission.

After drug treatment, patients could achieve remission or fail treatment and progress to surgery. In the absence of evidence on patient outcomes following different treatments, all patients achieving remission were assumed to maintain symptom free remission during the first cycle. During the second cycle, patients achieving remission either maintained the remission for the rest of the 12 months period or lost response and underwent colectomy. After surgery, patients could achieve surgical remission or suffer from surgical complications, undergo repeat surgery, and achieve surgical remission afterwards. Once patients were in the surgical remission, they were assumed to stay in that state. It was assumed that postsurgery complications would occur immediately after surgery and therefore in the same cycle as surgery. Patients treated for postsurgery complications were assumed to recover in the following cycle, achieve postsurgical remission and remain in remission for the rest of the analysis. Schematic presentation of the base case decision tree model is shown in Fig. 2.

The economic analysis was conducted with the perspective of the Nederland national payer for the reference year 2010 following Dutch guidelines for pharmacoeconomic evaluations

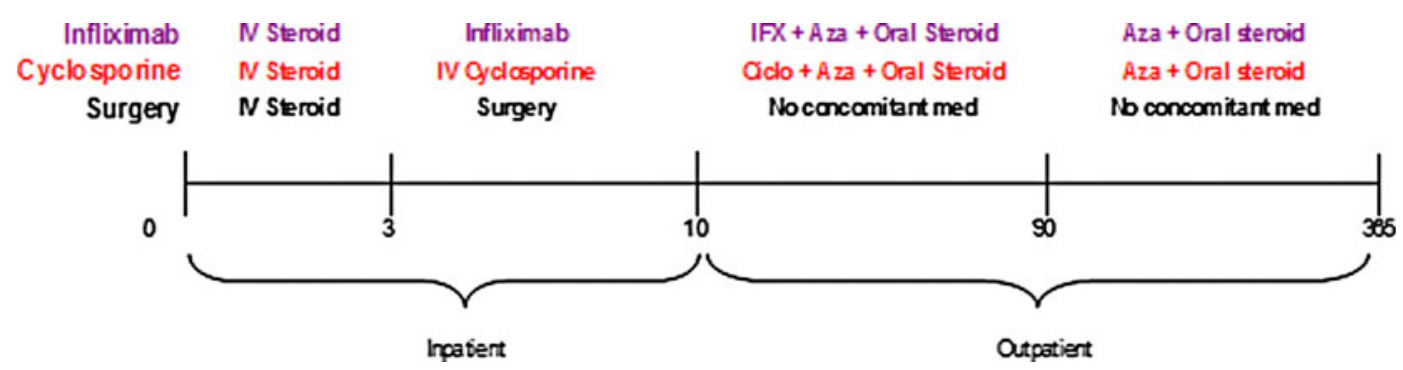

Fig. 1 Treatment options and treatment pathways. $A z a$ azathioprine, $C i c l o$ cyclosporine, $I F X$ infliximab, $I V$ intravenous 


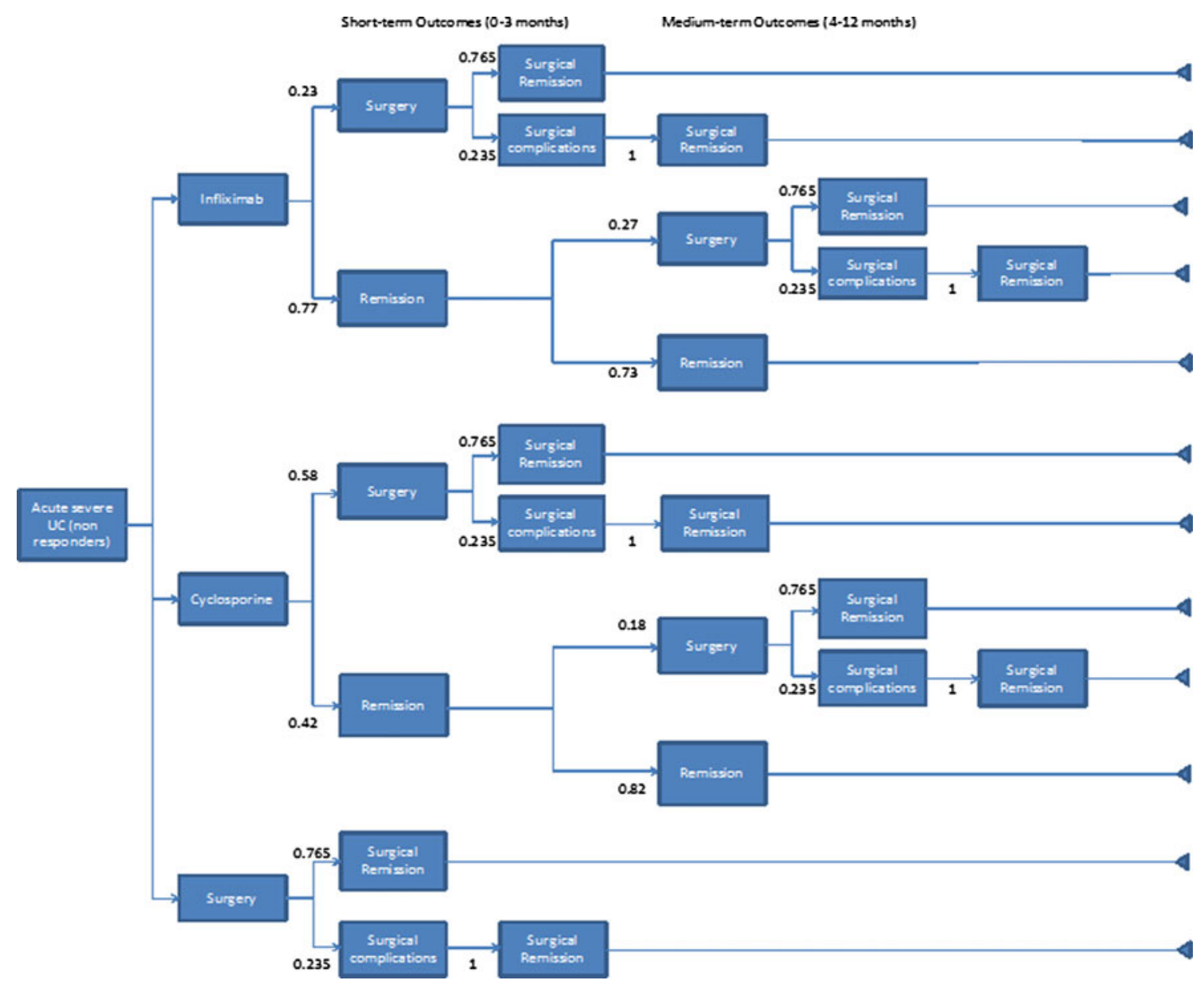

Fig. 2 Decision tree model for patients with acute exacerbations of ulcerative colitis (UC) (health states and decisions for cyclosporine and infliximab treatments are similar)

$[18,19]$. Costs and effects were discounted at 4 and $1.5 \%$ a year respectively. The primary effectiveness measure used in the analysis was quality-adjusted life years (QALYs).

To study the effects of the uncertainty around the modeling parameters on the final outcomes, deterministic as well as probabilistic sensitivity analyses were carried out. Deterministic sensitivity analyses were carried out by setting the model parameters (baseline body weight, utility weights and time horizon) equal to more extreme predetermined values. For the probabilistic sensitivity analysis, probability distributions of input parameters (transition probabilities, costs, utilities) were used. Beta distribution was used to model the variability in transition probabilities and utilities and Gamma distribution for costs.

\section{Long-term Follow-up}

Beyond the first year, a Markov model was used to predict the outcomes over a period of up to 10 years as part of the sensitivity analysis to assess the uncertainty around the time horizon (see Fig. 3). The probabilities of colectomy for the period 4-12 months were repeated to model the experience of patients in remission after the first year. Patients could remain in remission indefinitely or lose response and undergo 
surgery. Here again, patients could achieve surgical remission or suffer from surgical complications, undergo repeat surgery with the possibility of achieving surgical remission afterwards.

\section{Treatment Comparators and Clinical Practice}

According to the Dutch guidelines for pharmacoeconomic research [18], a drug should be compared with the standard or usual treatment for which effectiveness has been proven. UC patients hospitalized with an acute exacerbation currently receive IV corticosteroids (for up to $72 \mathrm{~h}$ ) in addition to their existing immunomodulator therapy. A total of $25 \%$ of these patients fail IV steroids and require further medical intervention [11, 20]. Following Dutch guidelines, cyclosporine and surgery were chosen as the treatment comparators [2, 20-23].

In general, patients with an acute exacerbation of UC will receive $72 \mathrm{~h} 40-60 \mathrm{mg}$ /day IV prednisolone. Patients refractory to the initial treatment are assumed to receive one of the three identified treatment strategies comprising infliximab, cyclosporine or surgical intervention. Responders to medical treatments were assumed to be discharged from the hospital on the 10th day and moved to an outpatient setting. Patients not responding to medical treatments on or before the 10th day were assumed to progress to surgery.

Infliximab treatment included a first infusion of $5 \mathrm{mg} / \mathrm{kg}$ of infliximab on day 4 , followed by additional $5 \mathrm{mg} / \mathrm{kg}$ infusion doses at week 2 and 6 after the first infusion. Patients on infliximab are expected to respond within 7 days of the first infusion. Following discharge from hospital, all infliximab responders received oral azathioprine ( $2 \mathrm{mg} / \mathrm{kg}$ ) for the rest of the 3-month period.

Patients receiving cyclosporine are given a $2 \mathrm{mg} / \mathrm{kg}$ daily dose of IV cyclosporine starting on day 4 for a period of 7 days. Following discharge from the hospital, cyclosporine responders are switched to an oral emulsion of cyclosporine $(5 \mathrm{mg} / \mathrm{kg} /$ day $)$ until 3 months (80 days in total) as a bridge to maintenance therapy with immunomodulator azathioprine ( $2 \mathrm{mg} / \mathrm{kg} /$ day) alone.

All patients on medical interventions who are still in remission after the first 3 months receive

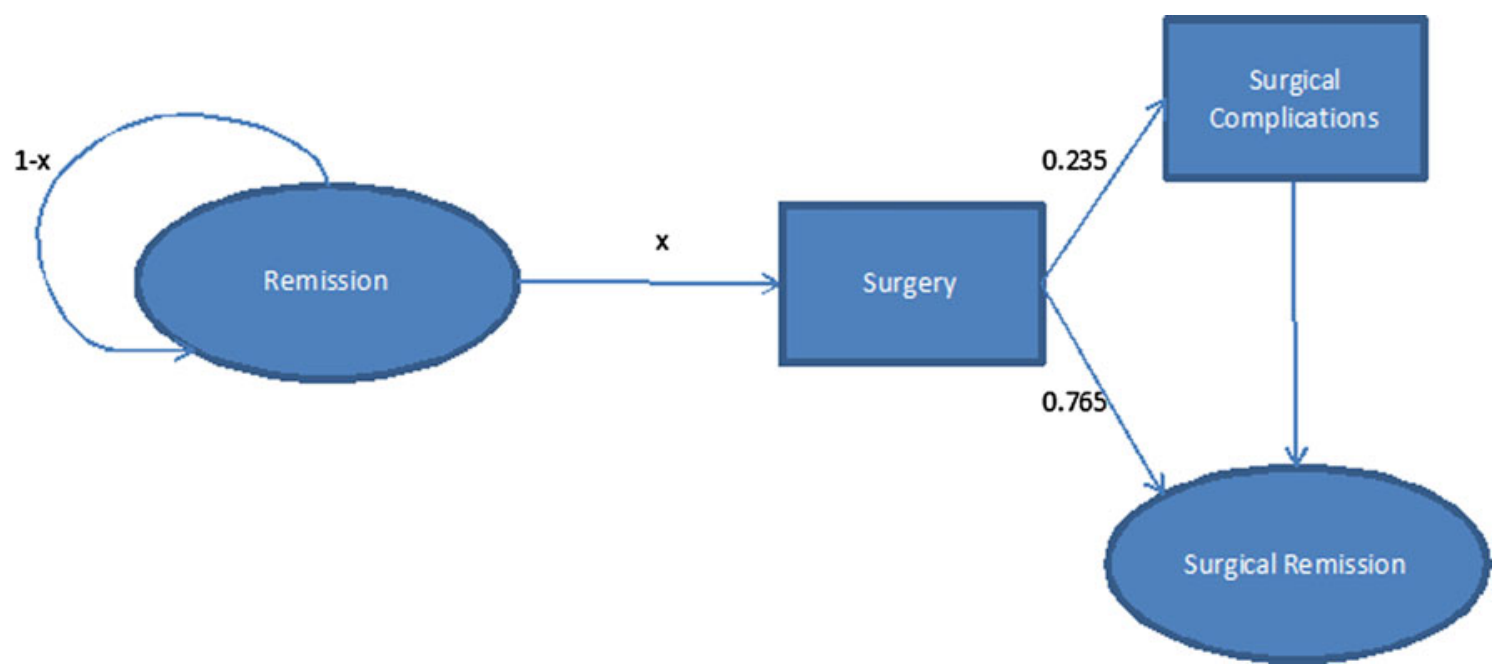

Fig. 3 Structure of Markov model for patients in remission after the first year 
the combination maintenance treatment of oral corticosteroids and azathioprine in the same dose as the first 3 months for the remainder of the analysis time frame [2].

Patients undergoing surgical intervention do not receive concomitant medication [2].

\section{Outcomes and Transition Probabilities}

The transition probabilities determined the proportion of patients in each health state over time. Because of the lack of any head-tohead trials between infliximab and cyclosporine, studies with placebo/steroids as a common comparator were selected. Colectomy rates used in the model were based on four studies which included acute severe and moderately severe UC patients admitted in a hospital [11, 12, 17, 24]. The patients in three studies $[11,12,17,24]$ were nonresponsive to IV corticosteroids whereas the patients in the fourth study [17] were not steroid refractory and received steroid therapy as a comparator instead of placebo.

The cumulated relative risk of disease progression on different treatment alternatives was expressed as a relative risk of a surgical procedure. For infliximab the efficacy estimates were derived from studies by Järnerot et al. [11] and Sands et al. [12] whereas for cyclosporine they were derived from D'Haens et al. [17] and Lichtiger et al. [24]. The overall combined risks were determined by an indirect comparison of available clinical trials $[13,25,26]$. The analysis dataset and the synthesized cumulative probabilities of colectomy at 3 and 12 months are presented in Tables 1 and 2 for Reference $[11,12,17,21,24]$.

The joint posterior distribution obtained from the indirect comparison was used to model the joint uncertainty in the transition probabilities to surgery, here by accounting for potential correlation between these parameters [27]. The model was run to simulated 1,000 cohorts of 1,000 patients in each treatment arm.

\section{Surgical Complications}

Postoperative wound infection, postoperative rectal stump complications, postoperative bleeding, postoperative sepsis, anastomotic leakage, small bowel obstruction and stoma complications were included to define the surgical complication. The overall aggregate rate of surgical complications was derived from the UK IBD audit [21].

\section{Patient Mortality}

Patient mortality was excluded from the model as a Dutch study shows that overall mortality rates for UC patients are comparable to the background population [28]. Not including mortality can be labeled as a conservative approach especially in the case where there might be a mortality risk associated with the surgical procedure in these UC patients.

\section{Risk of Side Effects}

The risk of side effects associated with either treatment with infliximab or cyclosporine was not included. Infusion-related reactions were the most common adverse reactions reported for infliximab. In clinical studies, approximately $20 \%$ of infliximab-treated patients experienced an infusion-related effect, only $3 \%$ of the patients discontinued treatment due to these effects and all patients recovered [2]. Other common $(\geq 1 / 100$ to $<1 / 10)$ side effects are headache, viral infections, fever, abdominal pain, rash, and increased transaminases [9]. Side effects associated with cyclosporine that occur very frequently $(\geq 1 / 10)$ are renal dysfunction, 
Table 1 Cumulative number of colectomies

\begin{tabular}{llccc}
\hline Study & Treatment & $\begin{array}{l}\text { Timepoint } \\
\text { (months) }\end{array}$ & $\begin{array}{c}\text { Number of } \\
\text { colectomies }\end{array}$ & Subjects at risk \\
\hline Järnerot et al. [11] & Placebo & 3 & 14 & 21 \\
& Infliximab & 3 & 7 & 24 \\
Sands et al. [12] & Placebo & 3 & 3 & 3 \\
Lichtiger et al. [24] & Infliximab & 3 & 0 & 3 \\
& Placebo & 3 & 4 & 9 \\
D'Haens et al. [17] & Cyclosporine & 3 & 3 & 11 \\
& Placebo & 3 & 3 & 15 \\
Järnerot et al. [11] & Cyclosporine & 3 & 3 & 14 \\
D'Haens et al. [17] & Placebo & 12 & 1 & 7 \\
& Infliximab & 12 & 3 & 17 \\
& Placebo & 12 & 3 & 12 \\
\hline
\end{tabular}

Table 2 Transition probabilities imputed in the models

\begin{tabular}{lcll}
\hline Probability & Estimate & SE & Source \\
\hline Surgery 0-3 months & 0.23 & & \\
$\quad$ Infliximab & 0.58 & 0.042 & Järnerot et al. [11] and Sands et al. [12] \\
Cyclosporine & & 0.049 & D'Haens et al. [17] and Lichtiger et al. [24] \\
Surgery 4-12 months & 0.27 & & \\
Infliximab & 0.18 & 0.065 & Järnerot et al. [11] \\
Cyclosporine & 0.23 & 0.057 & D'Haens et al. [17] \\
Surgical complications & & 0.030 & UK IBD Audit 2006 [21] \\
\hline
\end{tabular}

$S E$ standard error

a Sum of postoperative wound infection, postoperative rectal stump complications, postoperative bleeding, postoperative sepsis, anastomotic leakage, small bowel obstruction and stoma complications

hypertension, hyperlipidemia, headache, and tremor [29]. Renal dysfunction in particular, with its high frequency, is a potential serious complication and should be monitored adequately [2]. Not including risk of side effects is most likely not in favor of infliximab concerning patients' quality of life as cyclosporine has a worse side effect profile compared to infliximab.

\section{UTILITIES}

The health-related quality of life weights associated with active UC, medical remission, 
surgical remission and surgical complications were obtained from the literature. The utility weights used in the base case analysis were derived from a UC patient survey carried out in Cardiff Hospital using the EQ-5D (Health outcomes data repository [HODaR]) [30]. Scores were converted into utility measures using a standard algorithm based on preferences from the general public [31]. Patient utilities were classified by indexing them with simple clinical colitis activity index (SCAI), into remission (SCAI: 0-2) and active UC (SCAI: 3 and above) [32]. Separate sets of utilities were available for ileal pouch anal anastomosis (IPAA) surgery and ileostomy, therefore a weighted average (29\% IPAA, 71\% ileostomy) was used as utility for surgical remission. This study did not capture utilities associated with postsurgery complications and was assumed to be the same as that of active UC patients. Health state utilities were also available from Arseneau et al. [33]. However, these utilities were based on patient preferences instead of general public estimates and were used in the sensitivity analysis. Table 3 [33] summarizes health state utility estimates used in the economic evaluation.

\section{COSTS}

In this pharmacoeconomic analysis, direct medical costs were included because reliable data on direct nonmedical costs were not available. Direct medical costs include drug costs and healthcare resource use costs (consultant visits, hospital stay, surgery, endoscopy, therapeutic drug monitoring, and daycare). Indirect costs inside the health care system which are not related to the active drug treatment were excluded. IBD patients in the Netherlands are related to lower labor participation rates and higher chronic work disability compared to the age- and gendermatched general population [8]; however, there are no data that measure the effect of treatment on the productivity losses. It is more likely that comparator treatments, which result in more surgeries and hospital days, lead to more production losses. Therefore, not including productivity losses may be labeled as a conservative approach.

All unit healthcare costs were based on the Dutch Manual for costing research [34] and accompanying unit cost table of the Health Care Insurance Board [5]. Costs were adjusted to the 2010 price level using the harmonized consumer price index figures [35].

\section{Drug Acquisition and Administration Costs}

The costs of comparator treatments and concomitant medications used in the analysis

Table 3 Utility estimates associated with health states of ulcerative colitis patients

\begin{tabular}{llll}
\hline & $\begin{array}{l}\text { HODaR (EQ-5D) } \\
\text { Mean (SE) }\end{array}$ & $\begin{array}{l}\text { Arseneau (TTO) [33] } \\
\text { Mean (SE) }\end{array}$ & $\begin{array}{l}\text { Arseneau (VRS) [33] } \\
\text { Mean (SE) }\end{array}$ \\
\hline Remission & $0.88(0.039)$ & $0.79(0.059)$ & $0.82(0.055)$ \\
Active UC & $0.42(0.093)$ & $0.49(0.072)$ & $0.41(0.071)$ \\
Surgical remission & $0.60(0.094)$ & $0.63(0.070)$ & $0.50(0.072)$ \\
Surgical complications & $0.42(0.093)$ & $0.49(0.072)$ & $0.41(0.071)$ \\
\hline
\end{tabular}

HODaR health outcomes data repository, $S E$ standard error, TTO time tradeoff, $U C$ ulcerative colitis, $V R S$ visual rating scale 
were based on the average doses used in the clinical trials. The unit costs for drugs were obtained from the 'KNMP (Koninklijke Nederlandse Maatschappij ter bevordering der Pharmacie) taxe September 2010' [36]. Prednisolone, infliximab and cyclosporine are all administered IV in the hospital whereas patients take oral cyclosporine and azathioprine at home. The unit costs of drug acquisition and administration and the estimated total costs per day, assuming an average patient body weight of $70 \mathrm{~kg}$, are shown in Table 4 [36, 37]. The number of days of treatment and the total drug costs for the infliximab, cyclosporine, and surgery treatment groups during the first 3 month cycle of treatment are shown in Table 5. Any patient undergoing surgical intervention had no need for further medication [2]. After the first 3 months, only patients who were still in remission received maintenance treatment of azathioprine in the same dose as the first 3 months.

\section{Surgical Procedures}

Surgery consisting of a proctocolectomy with an ileoanal pouch, is standard treatment for patients not responding to therapy, usually performed in two separate operations $[2,15$, 16]. Costs for these procedures were not available from Dutch sources; therefore costs of comparable procedures from the UK were used in the model. Costs are comprised of two surgical interventions, ileostomy $(€ 1,320.38)$ and colectomy with ileorectal anastomosis $(€ 2,728.64)$ [26].

\section{Healthcare Resource Use}

Healthcare resource unit costs (2010 figures), number of days of use and overall cost estimates in the first 3 months are shown in Table 6 [26, 34].

All patients with an acute exacerbation are assumed to have an endoscopy when they are admitted into the hospital to evaluate the

Table 4 Drug cost estimates per day for a $70 \mathrm{~kg}$ patient in 2010

\begin{tabular}{llllll}
\hline & Prednisolone IV & Infliximab IV & Cyclosporine IV & Cyclosporine PO & Azathioprine PO \\
\hline Unit costs [36] (AIP $\left.{ }^{\mathrm{a}}\right)$ & $€ 26.40$ & $€ 647.08$ & $€ 33.14$ & $€ 159.36$ & $€ 11.66$ \\
Pack size & 10 & 1 & 10 & 50 & 50 \\
Strength & $25 \mathrm{mg} / \mathrm{mL}$ & $100 \mathrm{mg} / \mathrm{mL}$ & $50 \mathrm{mg} / \mathrm{mL}$ & $100 \mathrm{mg} / \mathrm{mL}$ & $50 \mathrm{mg}$ \\
Dose & $60 \mathrm{mg}$ & $5 \mathrm{mg} / \mathrm{kg}$ & $2 \mathrm{mg} / \mathrm{kg}$ & $5 \mathrm{mg} / \mathrm{kg}$ & $2 \mathrm{mg} / \mathrm{kg}$ \\
Drug costs/day (AIP $\left.{ }^{\mathrm{a}}\right)$ & $€ 6.34$ & $€ 2,264.78$ & $€ 9.28$ & $€ 11.16$ & $€ 0.65$ \\
Costs/90 days & - & - & - & $€ 1,003.97$ & $€ 58.77$ \\
Prescription cost [37] & - & - & - & $€ 7.91$ & $€ 7.91$ \\
Clawback (8.53\%) [37] & - & - & - & $€ 6.80$ & $€ 5.01$ \\
VAT (6\%) & - & - & - & $€ 60.30$ & $€ 3.70$ \\
Drug cost/day & $€ 6.34$ & $€ 2,264.78$ & $€ 9.28$ & $€ 11.84$ & $€ 0.73$
\end{tabular}

$I V$ intravenous, $P O$ per os (oral administration)

a Apotheek inkoopprijs 
Table 5 Total drug treatment cost (2010 figures) estimates during the first 3 months based on a typical $70 \mathrm{~kg}$ patient

\begin{tabular}{lcccc}
\hline Drug & Costs/day $(\boldsymbol{\epsilon})$ & \multicolumn{2}{l}{ Days of treatment, first 3 months } \\
\cline { 3 - 5 } & & Infliximab & Cyclosporine & Surgery \\
\hline Infliximab IV & $2,264.78$ & 3 & 0 & 0 \\
Cyclosporine IV & 9.28 & 0 & 7 & 0 \\
Cyclosporine PO & 11.84 & 0 & 80 & 0 \\
Prednisolone IV & 6.34 & 3 & 3 & 3 \\
Azathioprine PO & 0.73 & 80 & 80 & 0 \\
Total costs (first 3 months) & & $€ 6,871.45$ & $€ 1,089.07$ & $€ 19.01$ \\
\hline
\end{tabular}

$I V$ intravenous, $P O$ per os (oral administration)

severity of UC and after achieving (surgical) remission in the first 3 months. Costs for a diagnostic endoscopy were calculated by taking the average of a colonoscopy (€307.78) and a sigmoidoscopy ( $€ 180.58)$, since both techniques are used for diagnosis of the exacerbation $[2,16]$. Ongoing surveillance with endoscopy only starts 8 years after diagnosis of UC or when dysplasia was already present at time of surgery. Surveillance would take place three times in the first decade $[2,38]$. These costs are not inserted in the model, since they have a minor impact on total costs.

The frequency of consultant visits during the first 3 months is shown in Table 7 whereas the ongoing consultant visits are assumed to take place once every 3 months.

Patients successfully treated with infliximab or cyclosporine are discharged from the hospital after 10 days. This estimate was based on the clinical trials of infliximab and cyclosporine and includes the first 3 days of IV steroids and a

Table 6 Healthcare resource unit costs (2010 figures), number of days of use and overall cost estimates in the first 3 months

\begin{tabular}{|c|c|c|c|c|}
\hline \multirow[t]{2}{*}{ Resource } & \multirow[t]{2}{*}{ Costs/unit $(€)$} & \multicolumn{3}{|c|}{ Days of use, first 3 months } \\
\hline & & Infliximab & Cyclosporine & Surgery \\
\hline Consult visit [34] & 70.65 & 2 & 2 & 3 \\
\hline Hospital day [34] & 402.62 & 10 & 10 & 20 \\
\hline Surgery [26] & $4,049.02$ & 0 & 0 & 1 \\
\hline Diagnostic endoscopy [26] & 244.18 & 2 & 2 & 2 \\
\hline TDM cyclosporine [26] & 104.65 & 0 & 10 & 0 \\
\hline Daycare infliximab [34] & 256.66 & 2 & 0 & 0 \\
\hline Total costs (first 3 months) & & $€ 5,169.21$ & $€ 5,702.37$ & $€ 12,801.81$ \\
\hline
\end{tabular}


Table 7 Base-case results

\begin{tabular}{lccccc}
\hline Treatment & Cost $(\boldsymbol{\epsilon})$ & QALY & $\Delta$ Cost $(\boldsymbol{\epsilon})$ & $\Delta$ QALYs & ICER $(\boldsymbol{\epsilon})$ \\
\hline Infliximab & 17,062 & 0.80 & - & - & - \\
Cyclosporine & 14,784 & 0.70 & 2,278 & 0.09 & 24,277 \\
Surgery & 13,979 & 0.58 & 3,083 & 0.21 & 14,639 \\
\hline
\end{tabular}

ICER incremental cost-effectiveness ratio, $Q A L Y$ quality-adjusted life year

7-day recovery period on rescue treatment following steroid failure. These trials reported that patients have a mean response time of 7 days following the initiation of treatment (range 1-14 days) [11, 12, 24] after which they are assumed to be discharged from the hospital. In case of surgical complications (e.g., postoperative wound infection, small bowel obstruction), an additional 10 days in the general ward are assumed to reflect the cost for the treatment of these complications.

Therapeutic drug monitoring of cyclosporine is performed using chromatography as this method is the standard for cyclosporine measurement [39]. Furthermore cyclosporine levels will be determined as scheduled in Lichtiger et al. [24] and Ouakaa-Kchaou et al. [40]. When patients receive IV cyclosporine, their cyclosporine levels are measured every 2 days. While on oral cyclosporine, patients' cyclosporine levels should be tested weekly for the first month, biweekly for the second month, and then every 3-4 weeks. Unit costs for a daycare visit are assumed to reflect the costs for the second and third administration of infliximab which occur when patients have already been discharged from the hospital.

\section{RESULTS}

The base case cost-effectiveness analyses comparing infliximab with cyclosporine and surgery are presented in Table 7 . When infliximab is compared to cyclosporine, the model predicts a cost-effectiveness ratio of $€ 24,277$ per QALY, based on incremental QALYs of 0.09 and incremental costs of $€ 2,278$. In the comparison of infliximab versus surgery the model estimates a cost-effectiveness ratio of $€ 14,639$ per QALY, based on incremental QALYs of 0.21 and incremental costs of $€ 3,083$. Oneway sensitivity analyses showed that the results were sensitive to changes in baseline body weight, utility estimates, and the time horizon of analysis (Table 8). The results of probabilistic sensitivity analysis are displayed in a costeffectiveness acceptability curve in Fig. 4. The acceptability curve showed that there was a 55 and $79 \%$ chance that infliximab was costeffective compared to cyclosporine and surgery, respectively, at the willingness to pay threshold of $€ 30,000$ per QALY.

\section{DISCUSSION}

Infliximab induction regimen was shown to be cost-effective treatment option for UC patients hospitalized with an acute exacerbation in the UK [13]. Using an updated version of the UK model, this pharmacoeconomic analysis estimated the costs and effects of infliximab versus cyclosporine and surgery as a rescue therapy for Dutch patients hospitalized with acute exacerbation of UC. 
Table 8 One-way sensitivity analysis results

\begin{tabular}{lllll}
\hline Scenario & Value & $\Delta$ Costs & $\Delta$ QALYs & ICER \\
\hline Changing utilities & & & & $€ 35,743$ \\
Infliximab versus cyclosporine & TTO & $€ 2,278$ & 0.06 & $€ 22,862$ \\
& VRS & $€ 2,278$ & 0.10 & $€ 22,440$ \\
Infliximab versus surgery & TTO & $€ 3,083$ & 0.14 & $€ 13,581$ \\
Changing baseline weight & VRS & $€ 3,083$ & 0.23 & $€ 16,145$ \\
Infliximab versus cyclosporine & $60 \mathrm{~kg}$ & & & $€ 32,408$ \\
& $80 \mathrm{~kg}$ & $€ 1,515$ & 0.09 & $€ 10,648$ \\
Infliximab versus surgery & $60 \mathrm{~kg}$ & $€ 3,041$ & 0.09 & $€ 18,630$ \\
Changing time horizon & $80 \mathrm{~kg}$ & $€ 2,243$ & 0.21 & $€ 29,647$ \\
Infliximab versus cyclosporine & & $€ 3,924$ & 0.21 & $€ 34,258$ \\
& 5 years & & & $€ 17,204$ \\
Infliximab versus surgery & 10 years & $€ 5,370$ & 0.16 & $€ 17,191$ \\
\hline
\end{tabular}

ICER incremental cost-effectiveness ratio, $Q A L Y$ quality-adjusted life year, TTO time tradeoff, $V R S$ visual rating scale

Sensitivity analyses suggest that the patient weight is an important factor affecting the cost-effectiveness of infliximab. This analysis used $70 \mathrm{~kg}$ as the weight of a typical adult UC patient; however the steroid refractory patients hospitalized with acute exacerbation might weigh significantly less than the patients in an outpatient setting thereby resulting in improved cost-effectiveness for infliximab.

The base-case analysis used an analysis time horizon of 1 year. The authors explored the impact of increasing the time horizon 5 and 10 years using constant treatment effects to evaluate the long-term costs and benefits. Note that the long-term extrapolation is based on the efficacy estimates from small sample sizes and is subject to a high degree of uncertainty.
Wherever data were not available, assumptions used were conservative adversely affecting infliximab's case against alternative treatments. For example, the full licensed induction dose of $5 \mathrm{mg} / \mathrm{kg}$ infliximab (infusions at week 0, 2, and 6) was used in this analysis whereas the colectomy rates pertained to a single infusion of infliximab. The authors assumed that the full induction dose would be at least as effective as a single infusion of infliximab. However, there is evidence that two or more infusions may be more effective than one single infusion [41]. Therefore the results based on the efficacy estimates of infliximab used in this analysis are likely to be conservative.

Patient mortality and the risk of side effects were excluded from the model because no 


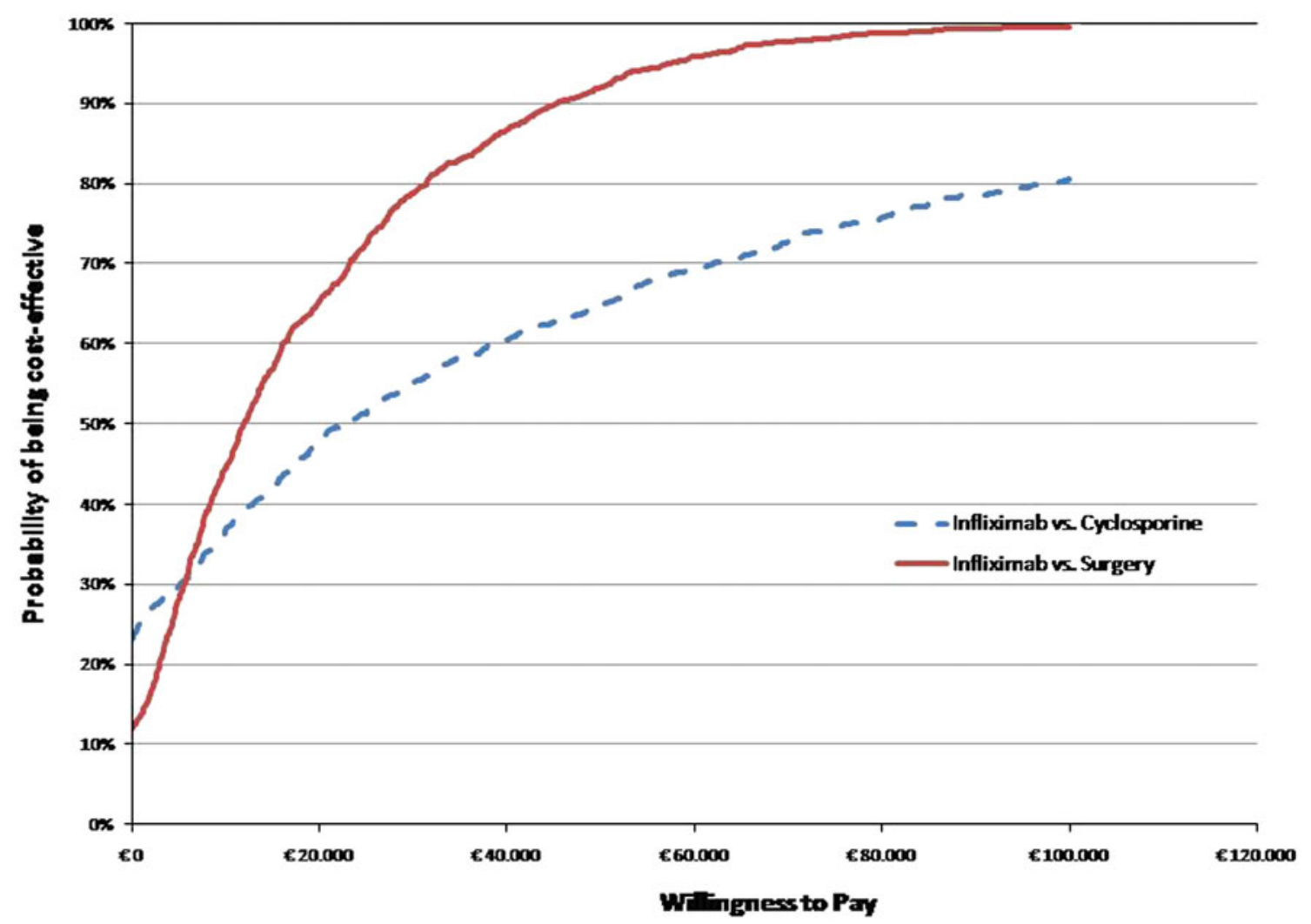

Fig. 4 Acceptability curve showing the probability that infliximab is cost-effective versus cyclosporine and surgery at a range of willingness to pay thresholds

information was available on the immediate side effects of infliximab in UC patients (ACT 1 and ACT 2) [10]. Not including these events can be considered conservative as it is expected that they occur less frequently when patients are treated with infliximab compared to treatment with cyclosporine or surgery. Cyclosporine is associated with a worse side effect profile than infliximab and surgery might be involved with a mortality risk. Not including risk of side effects and mortality is likely to result in conservative estimates of the costeffectiveness of infliximab versus cyclosporine and surgery.

In the absence of reliable data, productivity losses were not included in the analysis. It is more likely that comparator treatments, which result in more surgeries and hospital days, lead to more production losses. Therefore, not including productivity losses may also be labeled as a conservative approach.

The current analysis has several limitations. In general, a model is an abstraction of reality and not expected to capture all aspects of disease progression under alternative treatment strategies. In the absence of direct comparative data on infliximab versus cyclosporine use in moderate to severe UC patients, an indirect comparison was undertaken with placebo/ steroids as the common comparator. One of the studies (D'Haens et al. [17]) used in the indirect comparison was not appropriate because neither the population nor the comparator treatment was in line with the 
other trials for infliximab and cyclosporine. The included patient population was not steroid refractory and cyclosporine treatment was compared to treatment with steroids instead of placebo. The D'Haens et al. [17] study was included as the best available evidence because no data were available for medium and long term efficacy of cyclosporine. The efficacy estimates were based on a small number of trials with small sample sizes introducing significant uncertainty in results. Several univariate and extensive probabilistic sensitivity analysis were conducted to explore uncertainty around the results. The results were exploratory in nature and should be interpreted with caution.

\section{CONCLUSION}

Infliximab $5 \mathrm{mg} / \mathrm{kg}$ is an effective and safe rescue therapy in patients hospitalized and experiencing an acute exacerbation of UC. As demonstrated by this economic analysis, infliximab induction regimen appears to be a cost-effective treatment option in comparison to cyclosporine and surgery for hospitalized patients with acute exacerbations of UC, refractory to IV corticosteroids, in the Netherlands.

\section{ACKNOWLEDGMENTS}

Dr. Chaudhary is the guarantor for this article, and takes responsibility for the integrity of the work as a whole. The work was funded by Merck \& Co., Inc.

Conflict of interest. Mohammad A. Chaudhary and Fan Tao are employees of Merck \& Co., Inc.
Open Access. This article is distributed under the terms of the Creative Commons Attribution Noncommercial License which permits any noncommercial use, distribution, and reproduction in any medium, provided the original author(s) and the source are credited.

\section{REFERENCES}

1. Romberg-Camps MJL, Bol Y, Dagnelie PC, et al. Fatigue and health-related quality of life in inflammatory bowel disease: results from a population-based study in the Netherlands: the IBD-South Limburg cohort. Inflamm Bowel Dis. 2010;16:2137-47.

2. Richtlijn diagnostiek en behandeling van inflammatoire darmziekten bij volwassen [In Dutch]. Nederlandse Vereniging van Maag-Darm-Leverartsen 2008. Available at: http://www.icc-ibd.com/upload/ files/IBD-volwassenen-definitief-november-2009.pdf. Accessed Oct 12, 2012.

3. Albersnagel FA, Dijkstra G. Inflammatoire darmziekten. Medische en psychologische aspecten [In Dutch]. Tijdschrift Psychologie en Gezondheid. 2007;35:24-35.

4. Feagan BG, Reinisch W, Rutgeerts $P$, et al. The effects of infliximab therapy on health-related quality of life in ulcerative colitis patients. Am J Gastroenterol. 2007;102:794-802.

5. College voor Zorgverzekeringen. Costing and Tariffs Medical Procedures. Available at: http://www.cvz.nl/en/cvz. Accessed Nov 14, 2012.

6. National Public Health Compass. Available at: http://www.nationaalkompas.nl/gezondheid-en-zie kte/ziekten-en-aandoeningen/spijsverteringsstelsel/ inflammatoire-darmziekten. Accessed Oct 12, 2012.

7. Odes S, Vardi H, Friger M, et al. Cost analysis and cost determinants in a European inflammatory bowel disease inception cohort with 10 years of follow-up evaluation. Gastroenterology. 2006;131:719-28.

8. Boonen A, Dagnelie PC, Feleus A, et al. The impact of inflammatory bowel disease on labor force participation: results of a population sampled case control study. Inflamm Bowel Dis. 2002;8:382-9.

9. Summary of product characteristics of infliximab. Available at: EMEA: http://www.ema.europa.eu/ ema/. Accessed Oct 12, 2012. 
10. Rutgeerts P, Sandborn WJ, Feagan BG, et al. Infliximab for induction and maintenance therapy for ulcerative colitis. N Engl J Med. 2005;353:2462-76.

11. Järnerot G, Hertervig E, Friis-Liby I, et al. Infliximab as rescue therapy in severe to moderately severe ulcerative colitis: a randomized, placebo-controlled study. Gastroenterology. 2005;128:1805-11.

12. Sands BE, Tremaine WJ, Sandborn WJ, et al. Infliximab in the treatment of severe, steroid refractory ulcerative colitis: a pilot study. Inflamm Bowel Dis. 2001;7:83-8.

13. Punekar YS, Hawkins N. Cost-effectiveness of infliximab for the treatment of acute exacerbations of ulcerative colitis. Eur J Health Econ. 2010; 11:67-76.

14. Tsai H, Punekar Y, Morris J, Fortun P. A model of the long term cost effectiveness of scheduled maintenance treatment with infliximab for moderate to severe ulcerative colitis. Aliment Pharmacol Ther. 2008;28:1230-9.

15. Polle SW, Van Koperen PJ, Van Berge Henegouwen MI, et al. Laparoscopische chirurgie voor inflammatoire darmziekten. Ned Tijdschr Geneeskd. 2009;153:1465.

16. Weersma R, van Dullemen H, Kleibeuker J, Ploeg R, Dijkstra G. De behandeling van ernstige colitis ulcerosa [In Dutch]. Ned Tijdschr Geneeskd. 2006;150:12-7.

17. D'Haens G, Lemmens L, Geboes K, et al. Intravenous cyclosporine versus intravenous corticosteroids as single therapy for severe attacks of ulcerative colitis. Gastroenterology. 2001;120:1323-9.

18. Dutch Healthcare Insurance Board. Guidelines for pharmacoeconomic research (updated version. Valid as from April 1st 2006). Diemen: Dutch Health Care Insurance board; 2006. Available at:http://www.cvz.nl/binaries/content/documents/ cvzinternet/en/documents/procedures/guidelinespharmacoeconomic-research.com. Accessed Nov 14, 2012.

19. ISPOR 2006 Guidelines on Health Economic Evaluations: Available at: http://www.ispor.org/ peguidelines/index.asp. Accessed Oct 28, 2011.

20. Carter M, Lobo A, Travis S. Guidelines for the management of inflammatory bowel disease in adults. Gut. 2004;53:v1.

21. Leiper K, Lowe D, Driscoll R, et al. UK IBD audit 2006: National results for the organisation and process of IBD care in the UK. Available at: http://www.rcplondon.ac.uk/sites/default/files/uk_ ibd_audit_2006_national_report_appendices_print_ copy.pdf. Accessed Oct 14, 2012.

22. Travis S, Stange E, Lémann $M$, et al. European evidence-based consensus on the management of ulcerative colitis: current management. J Crohn's Colitis. 2008;2:24-62.

23. Woude JV. Medicamenteuze therapie van inflammatoire darmziekten. I. Colitis ulcerosa [In Dutch]. Geneesmiddelenbulletin. 2006;40:17-24.

24. Lichtiger S, Present DH, Kornbluth A, et al. Cyclosporine in severe ulcerative colitis refractory to steroid therapy. $\mathrm{N}$ Engl J Med. 1994;330:1841-5.

25. Bryan S, Andronis L, Hyde C, Connock M, FrySmith A, Wang D. Infliximab for the treatment of acute exacerbations of ulcerative colitis. Health Technol Assess. 2010;14:9.

26. Infliximab for acute exacerbation of ulcerative colitis. NICE technology appraisal guidance TA163. Available at: http://guidance.nice.org.uk/ TA163. Accessed Jun 10, 2012.

27. Ades AE, Welton NJ, Caldwell D, Price M, Goubar A, $\mathrm{Lu}$ G. Multiparameter evidence synthesis in epidemiology and medical decision-making. J Health Serv Res Policy. 2008;13:12-22.

28. Romberg-Camps M, Kuiper E, Schouten L, et al. Mortality in inflammatory bowel disease in the Netherlands 1991-2002: results of a population based study: the IBD South Limburg cohort. Inflamm Bowel Dis. 2010;16:1397-410.

29. Summary of product characteristics of cyclosporine. CBG-MEB. Available at: http://www.cbg-meb.nl/ CBG/nl/humane-geneesmiddelen/geneesmiddelen informatiebank. Accessed Nov 14, 2012.

30. Woehl A, Hawthorne A, Morgan C, Punekar Y, McEwan P. PG113: The epidemiology and health care resource use in patients with Crohn's Disease: a population based UK study. Value Health. 2007; 10:A355.

31. Dolan P. Modeling valuations for EuroQol health states. Med Care. 1997;35:1095-108.

32. Walmsley RS, Ayres RCS, Pounder RE, Allan RN. A simple clinical colitis activity index. Gut. 1998;43:29-32.

33. Arseneau KO, Sultan S, Provenzale DT, et al. Do patient preferences influence decisions on treatment for patients with steroid-refractory ulcerative colitis? Clin Gastroenterol Hepatol. 2006;4:1135-42. 
34. Oostenbrink JB. Handleiding voor kostenonderzoek (geactualiseerde versie 2004) [In Dutch]. Rotterdam: iMTA; 2004.

35. Centraal Bureau voor de Statistiek (CBS), Statline Available at: http://statline.cbs.nl/StatWeb/. Accessed Oct 12, 2012.

36. Z-index. Taxe WTG-geneesmiddelen. Sept. 2010. Available at: http://www.z-index.nl. Accessed Nov 14, 2012.

37. Nederlandse Zorgautoriteit (NZA). Available at: http:// www.nza.nl/zorgonderwerpen/zorgonderwerpen/ apotheekzorg. Accessed Nov 14, 2012.

38. Higgins PDR, Schwartz M, Mapili J, Zimmermann EM. Is endoscopy necessary for the measurement of disease activity in ulcerative colitis? Am J Gastroenterol. 2005;100:355-61.

39. Aberra F, Lichtenstein G. Review article: monitoring of immunomodulators in inflammatory bowel disease. Aliment Pharmacol Ther. 2005;21:307-19.

40. Ouakaa-Kchaou A, Gargouri D, Elloumi H, Kharrat J, Ghorbel A. Ciclosporin for severe refractory colitis. Tunis Med. 2010;88:390-3.

41. Kohn A, Daperno M, Armuzzi A, et al. Infliximab in severe ulcerative colitis: short term results of different infusion regimens and long term follow up. Aliment Pharmacol Ther. 2007;26:747-56. 